\title{
Heavy metals in the environment: sources, interactions and human health
}

\author{
Sergio Cinnirella • Ian M. Hedgecock • \\ Francesca Sprovieri
}

Received: 13 December 2013 / Accepted: 18 December 2013 / Published online: 10 January 2014

(C) Springer-Verlag Berlin Heidelberg 2014

This Special Issue of Environmental Science and Pollution Research collects together a number of contributions originally presented at the 16th International Conference on Heavy Metals in the Environment (ICHMET), held in Rome from the 23rd to the 27th of September 2012. The ICHMET series of conferences, which began in Toronto, Canada in 1975, has a history of being interdisciplinary, covering a range of environmental and biological media and the gamut of toxic metals. The 2012 conference was no exception, although the imminence of the fifth session of the Intergovernmental Negotiating Committee (INC) to prepare a global legally binding instrument on mercury, which was held in Geneva in January 2013, and led to the Minamata Convention on Mercury, obviously meant that mercury was a major talking point during the conference.

The Conference agenda included numerous sessions on toxic metals in environmental media, food and their impact on human and ecosystem well being, as well as biomonitoring, remediation and analytical techniques. The inclusion of some new sessions, however, set ICHMET 16 apart from previous conferences in the series. Given the, at the time forthcoming, United Nations Environment Program (UNEP) global mercury assessment 2013 (http://www.unep.org/publications/contents/ pub_details_search.asp? $I D=6282$ ), the fifth INC meeting and

\footnotetext{
Responsible editor: Philippe Garrigues

S. Cinnirella $\cdot$ I. M. Hedgecock $(\triangle) \cdot$ F. Sprovieri

CNR Institute of Atmospheric Pollution Research (Rende Section), c/o UNICAL, Rende 87036, Italy

e-mail: i.hedgecock@iia.cnr.it

S. Cinnirella

e-mail: s.cinnirella@iia.cnr.it

F. Sprovieri

e-mail: f.sprovieri@iia.cnr.it
}

the Minamata convention (http://www.mercuryconvention.org/) , there was a session dedicated to the UNEP Global Mercury Partnership (http://www.unep.org/hazardoussubstances/ Mercury/GlobalMercuryPartnership/tabid/1253/Default.aspx) and also sessions based on the first results from the EU funded Global Mercury Observation System project (www.gmos.eu).

Another new inclusion in the conference program for ICHMET 16 were the two sessions on interoperability, which highlighted the importance of data availability, comparability, accessibility and visibility within coordinated observational networks such as GEO/GEOSS (http://www.earthobservations. org/geoss.shtml). These themes were further developed in the sessions dedicated to 'Merging Science and Policy'. Three short courses before the official opening of the conference gave attendees the chance to broaden their knowledge of 'Data publishing and Interoperability technologies enabled by GEOSS', which was facilitated by Dr. Stefano Nativi, from the Institute of Atmospheric Pollution Research (CNR-IIA), Italy, 'Non-traditional Stable Metal Isotopes in the Environmental Sciences' with Dr. Oleg Pokrovsky from the Laboratory of Georesources and Environment, Toulouse (CNRS), France and also 'The Mercury Game: A Role-Playing Simulation about the role of science in international policy' facilitated by Prof. Noelle Selin from the Massachusetts Institute of Technology (MIT), USA.

This Special Issue cannot hope to encompass the diversity and the originality of the research presented at ICHMET 16; however, as editors, we hope that the Research Articles collected here will encourage environmental scientists to consider participating in the next ICHMET, which is to be held in Guiyang, China from the 22nd to the 26th of September 2014.

The articles in this Special Issue cover issues concerning metals associated with atmospheric particulate matter, seasonal variation in particulate composition and spatial variation 
of their dry and wet deposition. There are articles on metals in atmospheric, terrestrial, marine, estuarine and riparian environments; both experimental and modelling studies are included. There are two articles on cutting edge techniques for the determination of metal concentrations in environmental samples, and finally, there are also two articles on the subject of interoperability and data management, the importance of which in leveraging the link between environmental science observation and environmental policy was mentioned earlier.

Articles by Perrino et al. and Canepari et al. have investigated the seasonal variability composition of particulate matter in the Po Valley region of Italy, an area where prolonged periods of atmospheric stability, particularly in winter can lead to high rates of secondary aerosol formation. Pietrodangelo et al. also studied aerosols from the Po Valley, and using SEM, EDX combined backscattered, and secondary electron microanalysis investigated the environment in which metals occur within atmospheric particulates. Lyman et al. measured the dry and wet deposition of $\mathrm{Hg}$ and other trace metals at a number of sites in Illinois and highlight the need to take into account the dry deposition of $\mathrm{Hg}$ particularly in the summer when estimating deposition fluxes. Bencardino et al. describe the results from fine and coarse particle analysis during a number of cruise campaigns in the Mediterranean.

The Mediterranean Region was the subject of an overview of spatial and temporal trends observed in $\mathrm{Hg}$ measurements made in the atmosphere, water and sediments by Kotnik et al., and the Mediterranean Sea Hg mass balance was the subject of a study by Žagar et al. Two atmospheric modelling papers by Gencarelli et al. and De Simone et al. describe some of the recent advances in regional and global modelling approaches to the study of the atmospheric $\mathrm{Hg}$ cycle.

The mobility of $\mathrm{Hg}$ at the sediment water interface is the subject of the article by Emili et al., while Aryault et al. have investigated the concentrations and isotope ratios of lead in 66 years of samples taken from the Seine river basin. Two studies look at metals in areas impacted by human activities, Feng et al. have studied the distribution of ten metals/ metalloids in soils in the vicinity of a smelter in China, while Horvat et al. describe their studies of $\mathrm{Hg}$ accumulation in ray species in the Gulf of Trieste.

To conclude, there are two articles related to the sessions on Interoperability/data management by Nativi et al. and Cinnirella et al. describing the implementation, uses, standards and some of the applications of interoperable systems to the environmental sciences.

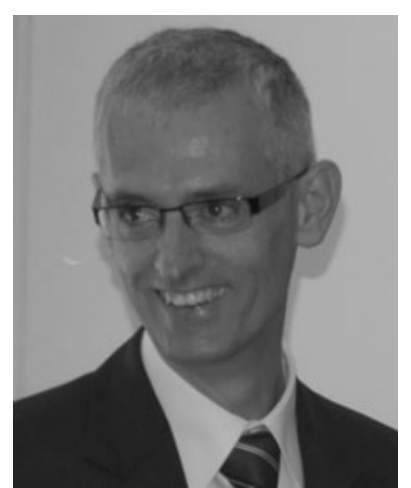

Sergio Cinnirella is research scientist at CNR-IIA (www.iia.cnr.i). $\mathrm{He}$ has 23 years of experience being involved in several national and international projects and as responsible of the GEO-Lab, oriented to develop methodologies and tools to link Science and Technology. Dr. Cinnirella is Head of Unit 3: Emission Inventories and Cyber(e)-Infrastructure of the National Reference Centre for Mercury (www.cnrmerc.org). He is peer reviewer for international scientific journals and projects and has published over 130 articles in a wide spectrum of media.

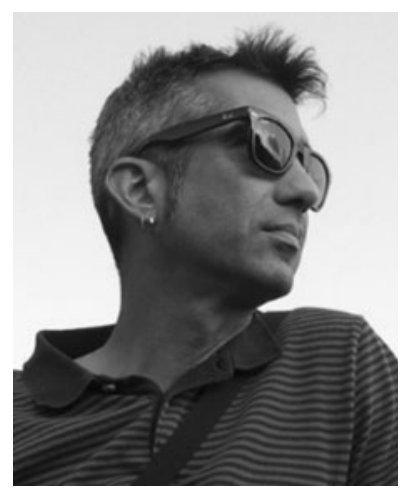

Ian M. Hedgecock moved to Italy nearly twenty years ago and has been a full time researcher for the Italian National Research Council since 2001. His main interests are in atmospheric chemistry and atmospheric chemistry modelling, and has been involved for some years in the study of the atmospheric $\mathrm{Hg}$ cycle.

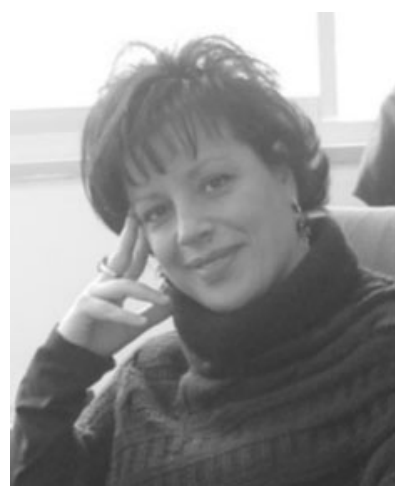

Francesca Sprovieri is research scientist at the Italian Research Council's Institute for Atmospheric Pollution Research. She is Principal Investigator, WP Leader and Participating Investigator in several research projects funded by national, European Union and international institutions, including Research, EU-DG EU-DG Environment, the Italian CNR and the Italian Ministry for Scientific Research. She has been involved for a number of years in research into the global biogeochemical cycle of $\mathrm{Hg}$ and has personally participated in numerous field campaigns in the Mediterranean, the Arctic and Antarctica. Among her current responsibilities is the coordination of the land based measurements Work Package in the GMOS project, which include monitoring stations throughout the northern and southern hemispheres. She is peer reviewer for international scientific journals and projects and author and/or co-author of over 160 publications in peer-reviewed journals, books and international reports. 